\title{
Synthesis and Characterization of Tin Oxide Nanopowder and Its Application to Sensing Different Pathogens
}

\author{
Akhil Chandran M. K., ${ }^{1}$ Branimir Bajac, ${ }^{2}$ Gregor Filipič, ${ }^{3}$ \\ Željka Cvejić, ${ }^{4}$ Vladimir V. Srdić, ${ }^{2}$ Milan Radovanović, ${ }^{1}$ \\ Mitar Simić, ${ }^{1,5}$ Sohail Sarang, ${ }^{1}$ and Goran M. Stojanović ${ }^{1 *}$ \\ ${ }^{1}$ Faculty of Technical Sciences, University of Novi Sad, Trg Dositeja Obradovića 6, 21000 Novi Sad, Serbia \\ ${ }^{2}$ Faculty of Technology, University of Novi Sad, Bulevar Cara Lazara 1, 21000 Novi Sad, Serbia \\ ${ }^{3}$ Jozef Stefan Institute, Jamova 39, Ljubljana, SI 1000, Slovenia \\ ${ }^{4}$ Faculty of Science, University of Novi Sad, Trg Dositeja Obradovića 3, 21000 Novi Sad, Serbia \\ ${ }^{5}$ Faculty of Electrical Engineering, University of Banja Luka, Patre 5, 78000 Banja Luka, Bosnia and Herzegovina
}

(Received October 29, 2020; accepted December 4, 2020)

Keywords: $\mathrm{SnO}_{2}$ nanopowder, sensor, impedance spectroscopy, pathogen detection

In this paper, we discuss the processing, fabrication, and characterization of tin oxide $\left(\mathrm{SnO}_{2}\right)$-based sensors for the detection of different pathogens. The sensing properties of $\mathrm{SnO}_{2}$ coatings sintered at three different temperatures $\left(600,700\right.$, and $\left.800{ }^{\circ} \mathrm{C}\right)$ were demonstrated by impedance microbiology. Sensors for the detection of Candida albicans and Pseudomonas aeruginosa were manufactured in the form of an interdigitated capacitor (IDC) structure. Electrochemical analysis revealed a change in impedance and a shift in self-resonant frequency (SRF) when the sensor was exposed to bacteria or yeast/fungi media. Structural and morphological characterizations of the nanostructured sensing films were carried out by various analytical techniques including X-ray diffraction, Raman spectroscopy, transmission electron microscopy (TEM), and scanning electron microscopy. The obtained results are promising for the fabrication of robust, cost-effective, and nontoxic $\mathrm{SnO}_{2}$-based sensors for detecting various pathogens.

\section{Introduction}

Metal oxides (MOs) and nanomaterials are preferred for the development of different sensors owing to their chemical stability and low production cost. ${ }^{(1,2)}$ Thick- and thin-film technologies have an essential role in the manufacturing of these sensors. ${ }^{(3,4)}$ Nanostructured metal oxides (NMOs) such as tin, titanium, zinc, iron, and indium oxides have attracted wide interest in the scientific community because they exhibit interesting characteristics such as biocompatibility, nontoxicity, naturally occurring nanostructures, and catalytic properties. In addition, MOs demonstrate enhanced electron transfer properties, thus improving sensing performances. ${ }^{(5)}$

Tin oxide $\left(\mathrm{SnO}_{2}\right)$ is an intrinsic n-type semiconductor with a band gap of around $3.6 \mathrm{eV}^{(6,7)}$ and a rutile tetragonal crystal structure. ${ }^{(8)} \mathrm{SnO}_{2}$ semiconductors have received significant attention in the fields of sensing, ${ }^{(9,10)}$ electronics, and catalysis. ${ }^{(11)}$ The popularity of $\mathrm{SnO}_{2}$

*Corresponding author: e-mail: sgoran@uns.ac.rs

https://doi.org/10.18494/SAM.2021.3090 
films is due to their good optical, electrical, and catalytic properties, as well as their ability to be prepared with various traditional deposition techniques such as sol-gel deposition, slurry deposition, physical vapor deposition, and chemical vapor deposition. Moreover, recent fabrication techniques have enabled the size reduction of $\mathrm{SnO}_{2}$-based sensors, increasing their sensitivity and reliability. These techniques include the ultrasonochemical, ${ }^{(12)} \mathrm{DC}$ sputtering, and vacuum evaporation methods. ${ }^{(13)}$ Despite the fact that very promising antibacterial, anticandidal, and cytotoxic activities have been reported, ${ }^{(12)}$ as well as $\mathrm{H}_{2}$ gas sensing properties, ${ }^{(13)}$ there is still strong interest in the development of synthesis and characterization processes for biomedical applications of $\mathrm{SnO}_{2}$ films. More precisely, a detailed understanding of the sensing mechanism of $\mathrm{SnO}_{2}$ in specific applications will identify the advantages and disadvantages of different fabrication methods and substrates. Such conclusions can enable the use of $\mathrm{SnO}_{2}$ films with enhanced properties in future devices. Because of this, new applications of $\mathrm{SnO}_{2}$-based sensors and their detailed analysis and characterization are very important for researchers in the field.

One of the ways to enhance the properties of $\mathrm{SnO}_{2}$ is by reducing the crystallite size to the nanometer range. ${ }^{(14,15)}$ The electron transfer mechanism is the most valuable property of MO semiconductors for sensor, electronic, and optical applications. ${ }^{(16)}$ The crystallite size, the nature of the surface, and the phase composition are the main parameters that determine electron transport through a material. ${ }^{(17,18)}$ Furthermore, it is important to develop an inexpensive processing method for realizing user-friendly and miniature devices. ${ }^{(19)}$ Thus, many researchers have recently invested effort in the development and fabrication of cost-effective and compact structures with excellent performances and stability to be used as gas sensors. ${ }^{(20,21)}$ The methods and procedures used for synthesis have a significant role in controlling the particle size ${ }^{(22,23)}$ to improve the performance of MO semiconductors. ${ }^{(24)}$ The influences of the temperature, pressure, and $\mathrm{pH}$ of the reaction medium and sintering process have been studied, ${ }^{(25)}$ and it has been concluded that they strongly affect the size of nanoparticles. $\mathrm{SnO}_{2}$ nanostructures have received particular attention in the development of sensors for the monitoring and detection of different pathogen systems owing to their biocompatibility and the efficient sensing. ${ }^{(26,27)}$ Recently, the detection of foodborne pathogens has been a focus of study owing to increased concerns about food safety and public health, ${ }^{(28,29)}$ motivating the development of various sensors for this purpose. The conventional procedure for identifying pathogens usually includes procedures such as culturing microbes and isolation from the pathogen medium, which may take several days to obtain a final result. ${ }^{(30)}$ To overcome this time delay, numerous methods for the detection of pathogens have been developed to reduce the assay time. ${ }^{(31,32)}$ One of the techniques for determining pathogens is impedance spectroscopy, and such a method of detection is called impedance microbiology. ${ }^{(33)}$ Stewart attempted to determine a microorganism by impedance measurement. ${ }^{(34)}$ After that, several papers described the impedance-based detection of microorganisms and pathogens. ${ }^{(35,36)}$ However, there is a lack of articles covering the complete process comprising synthesis of the nanostructured material, creation of the sensing film, manufacturing of the sensor, and its comprehensive characterization and validation.

As reported in this paper, we studied the synthesis and characterization of a $\mathrm{SnO}_{2}$ nanopowder as well as the sensing performance of $\mathrm{SnO}_{2}$ films sintered at three different 
temperatures $\left(600,700\right.$, and $\left.800{ }^{\circ} \mathrm{C}\right)$. We found that sensing films sintered at the lowest temperature $\left(600^{\circ} \mathrm{C}\right)$ had the smallest grains and the lowest self-resonant frequency (SRF). Such characteristics are key factors enabling the use of low-cost measurement devices because of the low value of the upper-frequency limit that is required. For testing purposes, we applied sensing films sintered at $600{ }^{\circ} \mathrm{C}$ to the detection of different pathogens (Candida albicans and Pseudomonas aeruginosa). Our results showed that $\mathrm{SnO}_{2}$ films exposed to different pathogens exhibit different patterns of impedance changes and SRF shifts, which can be detected by very simple readout electronics, making these films suitable for in situ measurements outside the laboratory.

\section{Materials and Methods}

\subsection{Synthesis of $\mathrm{SnO}_{2}$ nanopowder}

A $1 \mathrm{M}$ solution of $\mathrm{SnO}_{2}$ was prepared by dissolving $\mathrm{Sn}(\mathrm{II}) \mathrm{Cl}_{2}$ (from Alfa Aesar, purity $98 \%$ ) into $90 \%$ absolute ethanol with continuous stirring at $60{ }^{\circ} \mathrm{C}$ for about $1 \mathrm{~h}$. The obtained solution was allowed to cool, and the precipitation of $\mathrm{SnO}_{2}$ was started by the dropwise addition of $\mathrm{NaOH}$ solution $(0.01 \mathrm{M})$. $\mathrm{NaOH}$ solution was added with continuous stirring until the $\mathrm{pH}$ reached 10. The product was collected in a centrifuge flask and washed with water and ethanol several times to remove undesired products from the $\mathrm{SnO}_{2}$ nanopowder. The resulting product was dried overnight in a drier at $70{ }^{\circ} \mathrm{C}$. The dried powder was collected in a mortar and ground to destroy the formed agglomerations. The powder product was treated at $500{ }^{\circ} \mathrm{C}$ in a tube furnace and a pale yellow fine powder of $\mathrm{SnO}_{2}$ was obtained after calcination (Fig. 1).

\subsection{Fabrication procedure of $\mathrm{SnO}_{2}$-based sensors}

The sensor samples were fabricated by screen-printing technology using a previously prepared paste. The paste was obtained by grinding the calcined $\mathrm{SnO}_{2}$ nanopowder using a

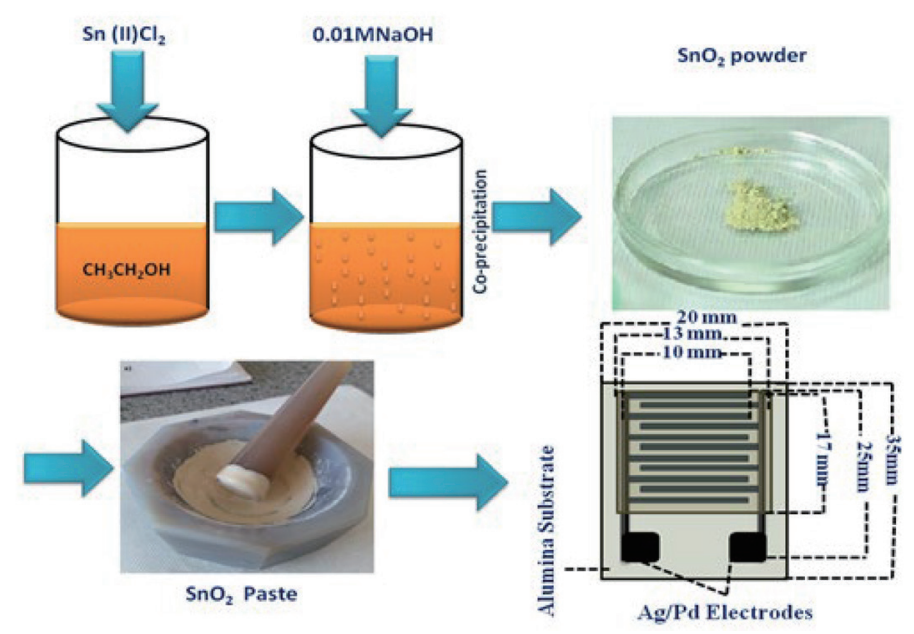

Fig. 1. (Color online) Steps in manufacturing $\mathrm{SnO}_{2}$ sensing layer on IDC on $\mathrm{Al}_{2} \mathrm{O}_{3}$ substrate. 
planetary ball mill in an isopropanol solvent, and three cycles of grinding were performed with a 1:3 mass ratio of the powder and the grinding ball. The ground powder was then evaporated overnight at $80{ }^{\circ} \mathrm{C}$. The $\mathrm{MO}$ paste was made by gently mixing the $\mathrm{SnO}_{2}$ nanopowder with a binder solution comprising ethyl cellulose and terpineol (1:9 ratio). In the first step of the fabrication, an interdigitated capacitor (IDC) electrode system was formed using a screenprinted $\mathrm{Ag} / \mathrm{Pd}$ metal layer on a previously cleaned alumina $\left(\mathrm{Al}_{2} \mathrm{O}_{3}\right)$ substrate. The IDC structure was composed of eight fingers on one side and eight fingers on the other side, representing the electrodes of a planar capacitor. The width of the conductive lines was $0.8 \mathrm{~mm}$ and the space between them was $0.6 \mathrm{~mm}$. This IDC layout and its dimensions were selected to obtain SRFs in the range up to $100 \mathrm{MHz}$, which is in the range of the HP-4194A commercial impedance analyzer as well as handheld readout electronic devices. The fabrication was completed with the deposition of the $\mathrm{SnO}_{2}$ paste by a screen printer (Fig. 1). The prepared samples were sintered at 600,700 , and $800{ }^{\circ} \mathrm{C}$ and are denoted as $\mathrm{SnO}_{2}-600, \mathrm{SnO}_{2}-700$, and $\mathrm{SnO}_{2}-800$, respectively.

\subsection{Microbial culture preparation}

C. albicans and $P$. aeruginosa pathogen samples were used as bulky media to analyze the sensing properties of $\mathrm{SnO}_{2}$ coatings, using colonies of $P$. aeruginosa cultured for $24 \mathrm{~h}$ on blood agar (HiMedia, India) and colonies of C. albicans cultured on Sabouraud dextrose agar (HiMedia, India). In sterile tubes, suspensions with a density of 0.5 MCF (McFarland) were created in $4.5 \mathrm{ml}$ of physiological saline in accordance with the European Committee on Antimicrobial Susceptibility Testing (EUCAST) standard.

\subsection{Characterization techniques}

The structure of the calcined $\mathrm{SnO}_{2}$ nanoparticles was analyzed by transmission electron microscopy (TEM) with a JEOL JEM 2100 electron microscope and an acceleration voltage of $200 \mathrm{kV}$. The surface morphology of the sintered $\mathrm{SnO}_{2}$ film was determined by scanning electron microscopy (SEM; JEOL JSM6460LV). The phase composition was determined and the structure was characterized by X-ray diffraction (XRD; Rigaku, MiniFlex 600) as well as Raman spectroscopy (Thermo Fisher DXR Raman microscope). The crystallite size was estimated from XRD patterns using the Scherrer equation. The impedance spectroscopic and sensing performance analyses of $\mathrm{SnO}_{2}$ films towards different pathogen media were conducted using an HP-4194A impedance analyzer (Fig. 2).

\section{Results and Discussion}

\subsection{Characterization of $\mathrm{SnO}_{2}$ nanopowder}

High-resolution TEM (HRTEM) and selected-area electron diffraction (SAED) images of the $\mathrm{SnO}_{2}$ powder are presented in Fig. 3. It can be seen that the calcined $\mathrm{SnO}_{2}$ powder is agglomerated and that the observed particles are single-crystalline with a tetragonal rutile 


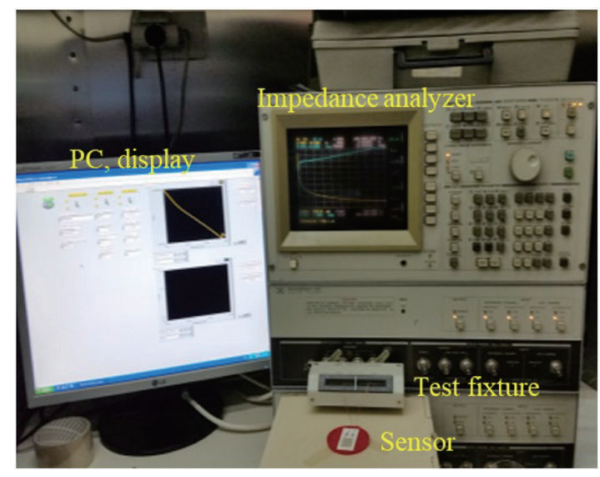

(a)

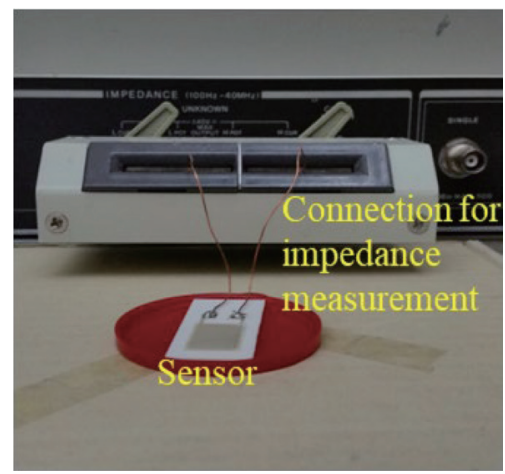

(b)

Fig. 2. (Color online) (a) Experimental setup for electrical impedance spectroscopy characterization of the fabricated sensor, and (b) connection of the sensor and the instrument for input impedance measurement.



Fig. 3. (Color online) (a) SAED image of $\mathrm{SnO}_{2}$ powder, (b) TEM image of $\mathrm{SnO}_{2}$ powder, (c) HRTEM image of $\mathrm{SnO}_{2}$ powder, and (d) HRTEM image of $\mathrm{SnO}_{2}$ powder.

structure and nanometer size (less than $25 \mathrm{~nm}$ on average). The particle size is very similar to that previously reported, ${ }^{(12)}$ where the size of the $\mathrm{SnO}_{2}$ nanoparticles was about 5-30 nm. Moreover, in Ref. 13, the nanostructures had diameters on the order of 10-100 nm and lengths on the order of $10 \mu \mathrm{m}$, depending on the type of substrate.

XRD measurements were performed to identify and confirm the crystalline phase of the $\mathrm{SnO}_{2}$ powder. The XRD spectrum of the calcined $\mathrm{SnO}_{2}$ powder is shown in Fig. 4(a), from which it can be seen that all the peaks are characteristic peaks of $\mathrm{SnO}_{2}$ powder without any secondary phase formation. The observed XRD peaks are ascribed to different planes, such as (110), (101), (200), and (211), indicating the formation of the rutile tetragonal structure. In previous 


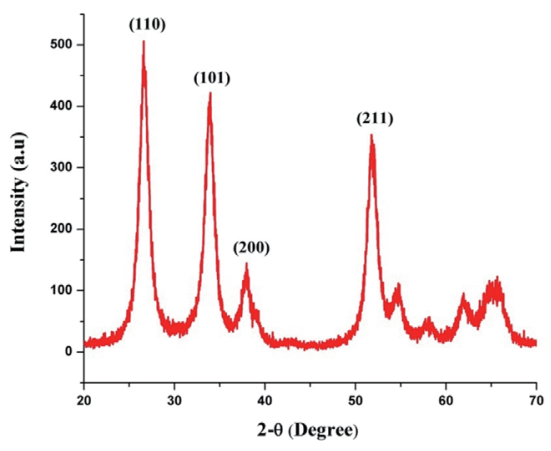

(a)

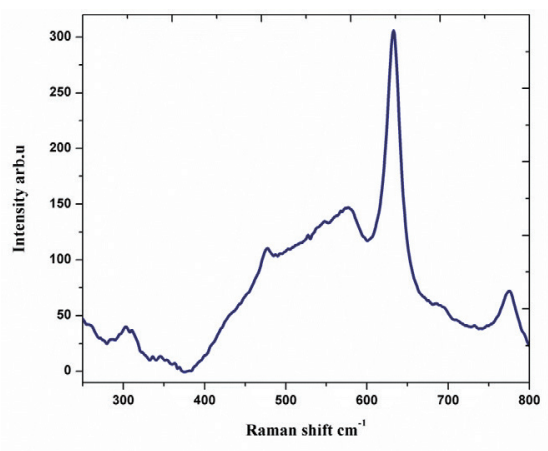

(b)

Fig. 4. (Color online) (a) XRD spectrum and (b) Raman spectrum of $\mathrm{SnO}_{2}$ powder.

studies, strong diffraction peaks ascribed to these planes confirmed the high crystallinity of structures fabricated by the ultrasonochemical method, ${ }^{(12)}$ as well as the DC sputtering and vacuum evaporation methods. ${ }^{(13)}$

The formation of $\mathrm{SnO}_{2}$ nanorods with a tetragonal rutile structure was also indicated by the Raman spectrum. $\mathrm{SnO}_{2}$ with the rutile structure belongs to the space group $\mathrm{P} 42 / \mathrm{mnm}$, 48-50 with $\mathrm{Sn}$ and $\mathrm{O}$ atoms in the 2a and 4f positions, respectively. Figure 4(b) depicts the Raman spectrum of the $\mathrm{SnO}_{2}$ nanorods in the wavenumber range of $300-850 \mathrm{~cm}^{-1}$. The Raman spectrum of the $\mathrm{SnO}_{2}$ nanorods exhibits the conventional vibration modes at 473, 498, 629, 689, and $770 \mathrm{~cm}^{-1}$.

\subsection{Structural characterization of $\mathrm{SnO}_{2}$ sensing layer}

The surface morphology and cross sections of the screen-printed $\mathrm{SnO}_{2}$ films were studied by SEM, and micrographs are presented in Fig. 5. Figures 5(a) and 5(b) show crosssectional views of the $\mathrm{SnO}_{2}$ sensing layer, IDC electrodes, and $\mathrm{Al}_{2} \mathrm{O}_{3}$ substrate. From the SEM micrograph in Fig. 5(a), the $\mathrm{SnO}_{2}$ sensing layer of $7.6 \mu \mathrm{m}$ thickness can be seen, which is clearly distinguishable from the electrode layer with a thickness of $9.5 \mu \mathrm{m}$ on the $\mathrm{Al}_{2} \mathrm{O}_{3}$ substrate. Moreover, from the SEM images, it can be seen that each layer is attached without voids to the adjacent layer(s), which explains the good adhesion of the $\mathrm{SnO}_{2}$ film and IDC electrode system on the $\mathrm{Al}_{2} \mathrm{O}_{3}$ substrate. Additionally, Fig. 5(c) shows the surface morphology of the $\mathrm{SnO}_{2}$ sensing coating, where a uniform structure can be observed. A top view of the interdigitated electrode structure can be seen in Fig. 5(d). XRD patterns of the $\mathrm{SnO}_{2}-600, \mathrm{SnO}_{2}-700$, and $\mathrm{SnO}_{2}-800$ samples are presented in Fig. 6. All the XRD peaks of the rutile tetragonal $\mathrm{SnO}_{2}$ structure can be observed. With increasing sintering temperature, the peak intensities increase and the full width at half maximum (FWHM) values decrease. ${ }^{(37)}$ These behaviors strongly indicate the enhanced crystallinity and increased grain size in $\mathrm{SnO}_{2}$.

The average crystallite sizes $\left(D_{p}\right)$ of the sintered $\mathrm{SnO}_{2}-600, \mathrm{SnO}_{2}-700$, and $\mathrm{SnO}_{2}-800$ samples were estimated with Scherrer's equation [Eq. (1)] using the FWHM as follows: 


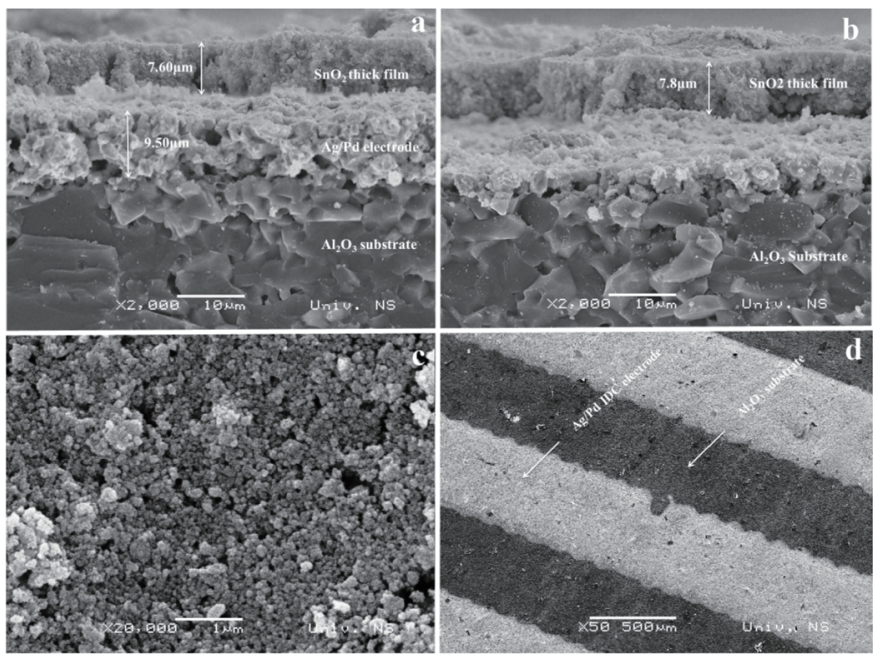

Fig. 5. SEM images of the sensor structure: $(\mathrm{a}, \mathrm{b})$ cross-sectional images, (c) surface of $\mathrm{SnO}_{2}$ layer, and (d) surface of IDC electrodes (fingers).

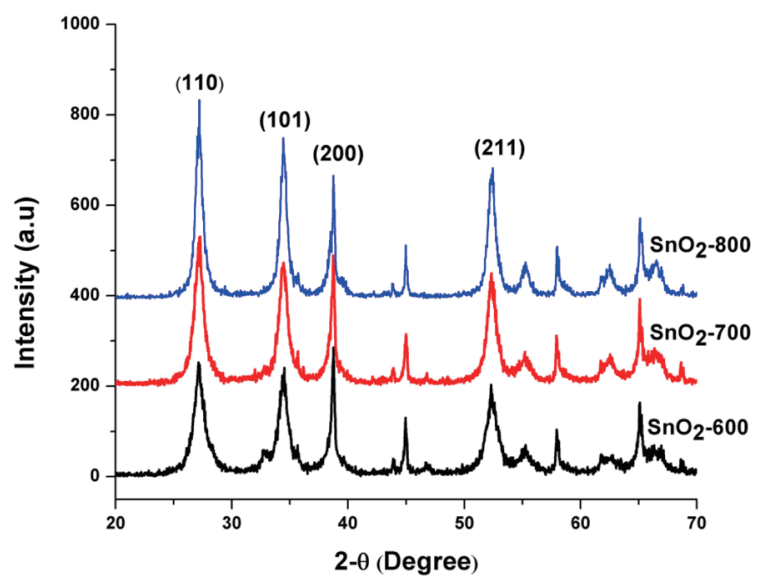

Fig. 6. (Color online) XRD spectra of $\mathrm{SnO}_{2}$ films $\left(\mathrm{SnO}_{2}-600, \mathrm{SnO}_{2}-700\right.$, and $\mathrm{SnO}_{2}-800$, sintered at 600, 700, and $800^{\circ} \mathrm{C}$, respectively).

$$
D_{p}=\frac{K \lambda}{\cos \theta \times \beta / 2}
$$

where $\beta$ is the peak broadening (i.e., FWHM) in radians, $\lambda$ is the XRD wavelength $(0.15405 \mathrm{~nm})$, $K$ is a constant $(K=0.94)$, and $\theta$ is the Bragg angle.

The average crystallite sizes of the samples sintered at 600,700 , and $800{ }^{\circ} \mathrm{C}$ were 16,18 , and $25 \mathrm{~nm}$, respectively (Table 1), confirming the expected increase in grain size with increasing sintering temperature. The same conclusion has already been reported by Pawar et al. ${ }^{(38)}$ for nanometer crystallite sizes. The nanometer particle size will enhance the sensitivity of the $\mathrm{SnO}_{2}$ active layer, as already reported. ${ }^{(37)}$ 
Table 1

Average crystallite size of $\mathrm{SnO}_{2}$ layer calculated using Scherrer's equation.

\begin{tabular}{lcccc}
\hline Sample & Sintering temperature $\left({ }^{\circ} \mathrm{C}\right)$ & FWHM $\left(^{\circ}\right)$ & Peak position $\left(^{\circ}\right)$ & Crystallite size $(\mathrm{nm})$ \\
\hline $\mathrm{SnO}_{2}-600$ & 600 & 0.525 & 27.1 & 16 \\
$\mathrm{SnO}_{2}-700$ & 700 & 0.465 & 27.2 & 18 \\
$\mathrm{SnO}_{2}-800$ & 800 & 0.330 & 27.1 & 25 \\
\hline
\end{tabular}

Raman spectra of the sintered $\mathrm{SnO}_{2}$ films are shown in Fig. 7. From the spectra, the formation of the $\mathrm{SnO}_{2}$ phase and all major characteristic bands of $\mathrm{SnO}_{2}$ can be confirmed. The Raman shifts observed at 632 and $472 \mathrm{~cm}^{-1}$ represent the $A_{1 g}$ and $E_{g}$ modes of vibration, respectively, whereas a Raman mode of vibration was observed at $572 \mathrm{~cm}^{-1}$. The Raman shift at $572 \mathrm{~cm}^{-1}$ occurs in $\mathrm{SnO}_{2}$ with a small grain size. This reveals that the crystallite size of the $\mathrm{SnO}_{2}$ sensing layer is in the nanometer range. ${ }^{(39,40)}$ These Raman active modes are the main characteristic of the $\mathrm{SnO}_{2}$ rutile structure. These spectra confirm that the $\mathrm{SnO}_{2}$ films were formed in the metal phase.

\subsection{Impedance spectroscopic analysis of the proposed sensors}

The validation of sensor performances by impedance spectroscopic analysis was performed in two parts as follows:

(1) Impedance and SRF measurements were performed on the sensors with $\mathrm{SnO}_{2}$ films sintered at three different temperatures $\left(600,700\right.$, and $\left.800{ }^{\circ} \mathrm{C}\right)$ when they were immersed in a solution of C. albicans. The aim of this experiment was to determine the influence of the sintering temperature on the sensor responses (impedance change and SRF) to the same pathogen. It was expected that the grain size, surface roughness, and surface area to volume ratio of the nanostructure would influence the sensing performances, providing valuable information regarding which sintering temperature provides the best sensing performances and enabling the development of low-cost impedance measurement devices for in situ applications.

(2) Impedance and SRF measurements were performed on the sensors with $\mathrm{SnO}_{2}$ films sintered at the same temperature when they were immersed in solutions with different pathogens $(P$. aeruginosa and $C$. albicans). It was expected that the results would provide clues on how $\mathrm{SnO}_{2}$ sensing films sintered at the same temperature responded to different pathogens. The presence of pathogens was expected to influence the permittivity/conductivity of the solution and sensing film, producing changes in the impedance and capacitance of the IDC sensor and consequently enabling the identification of specific pathogens through the measured SRF.

As mentioned above, impedance and SRF measurements were performed with an HP4194A impedance analyzer. The impedance was measured at 60,120,180, and $240 \mathrm{kHz}$ at room temperature. The obtained results are provided and discussed in the following subsections. 


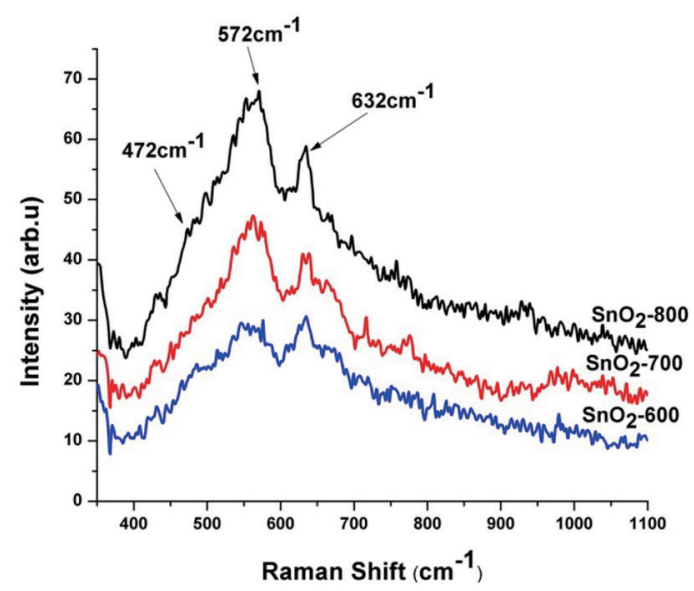

Fig. 7. (Color online) Raman spectra of $\mathrm{SnO}_{2}$ films sintered at 600,700 , and $800{ }^{\circ} \mathrm{C}$.

\subsubsection{Influence of sintering temperature on sensor response to $C$. albicans}

The obtained impedance magnitudes and phase angles of the $\mathrm{SnO}_{2}$ films sintered at three sintering temperatures $\left(600,700\right.$, and $\left.800{ }^{\circ} \mathrm{C}\right)$ when they were exposed to a solution with $C$. albicans are shown in Tables 2 and 3, respectively. The sensor impedance magnitude increased with the sintering temperature at all test frequencies, whereas the impedance phase angle mostly decreased.

Figure 8 presents the capacitance as a function of frequency for the three sensor samples exposed to C. albicans. It can be concluded that the SRF increases with increasing sintering temperature.

The higher impedance at the higher sintering temperature indicates that the IDC sensor has lower capacitance and consequently a higher SRF, which means that Fig. 8 supports the values in Table 2. However, because in this experiment the solution was not changed during the measurement, relative changes in impedance should be linked to the influence of the grain size, surface roughness, and surface area to volume ratio of the nanostructure on the sensing performance.

Table 1 shows that the average grain size of the $\mathrm{SnO}_{2}$ films increased with increasing sintering temperature. It has already been reported that increasing the grain size reduces the porosity of MO films, because the size of grain boundaries decreases as very small pores disappear through diffusion kinetics, whereas the porosity of samples with a smaller grain size is mostly intergranular. ${ }^{(41)}$ Moreover, in Ref. 42, it was shown that the MO structure is homogeneous for a larger grain size and that a more porous structure has a higher capacitance. This means that the sensing film sintered at the lowest temperature $\left(600{ }^{\circ} \mathrm{C}\right)$ in our experiment should exhibit the highest capacitance, and consequently, the lowest SRF, and the sensing film sintered at the highest temperature $\left(800{ }^{\circ} \mathrm{C}\right)$ should exhibit the lowest capacitance and the highest SRF. We obtained such results, as shown in Fig. 8. Moreover, the results in Table 2 are 
Table 2

Measured impedance magnitudes $Z(\Omega)$ of the sensors sintered at different temperatures.

\begin{tabular}{lcccc}
\hline $\begin{array}{l}\text { Sintering } \\
\text { temperature }\left({ }^{\circ} \mathrm{C}\right)\end{array}$ & $Z(\Omega)$ at $60 \mathrm{kHz}$ & $Z(\Omega)$ at $120 \mathrm{kHz}$ & $Z(\Omega)$ at $180 \mathrm{kHz}$ & $Z(\Omega)$ at $240 \mathrm{kHz}$ \\
\hline 600 & 11.852 & 11.719 & 11.663 & 11.632 \\
700 & 13.327 & 13.160 & 13.090 & 13.050 \\
800 & 16.998 & 16.823 & 16.749 & 16.712 \\
\hline
\end{tabular}

Table 3

Measured impedance phase angles $\phi(\mathrm{deg})$ of the sensors sintered at different temperatures.

\begin{tabular}{lcccc}
\hline $\begin{array}{l}\text { Sintering } \\
\text { temperature }\left({ }^{\circ} \mathrm{C}\right)\end{array}$ & $\phi(\mathrm{deg})$ at $60 \mathrm{kHz}$ & $\phi(\mathrm{deg})$ at $120 \mathrm{kHz} \phi(\mathrm{deg})$ at $180 \mathrm{kHz} \phi(\mathrm{deg})$ at $240 \mathrm{kHz}$ \\
\hline 600 & -1.938 & -0.938 & -0.332 & 0.161 \\
700 & -1.935 & -1.045 & -0.477 & -0.016 \\
800 & -2.086 & -1.096 & -0.541 & -0.131 \\
\hline
\end{tabular}

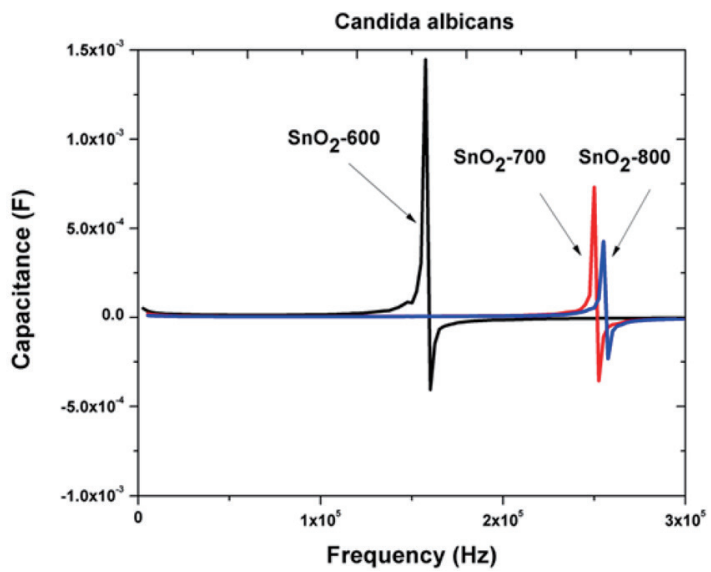

Fig. 8. (Color online) Capacitance as a function of frequency for $\mathrm{SnO}_{2}-600, \mathrm{SnO}_{2}-700$, and $\mathrm{SnO}_{2}-800$ in $C$. albicans medium.

in agreement with those in Fig. 8 as there is an increase in impedance with increasing sintering temperature, which means that the sensing film sintered at the lowest temperature had the highest capacitance.

From Fig. 8, it can be concluded that the lowest sintering temperature corresponds to the lowest SRF value. The advantage of a lower SRF is the reduced complexity of the required measurement device, and therefore its cost, as it requires a lower upper-frequency limit, which is very important for in situ measurements outside the laboratory. For this reason, we next analyzed the response of $\mathrm{SnO}_{2}-600$ films to exposure to different pathogens.

\subsubsection{Influence of pathogen medium (C. albicans or $P$. aeruginosa) on response of $\mathrm{SnO}_{2}$ sensor sintered at $600{ }^{\circ} \mathrm{C}$}

The obtained results for the impedance magnitude and phase angle of sensors sintered at $600{ }^{\circ} \mathrm{C}$ when they were immersed in solutions with C. albicans and P. aeruginosa are shown 
in Table 4. The sensors had lower impedance magnitudes when they were immersed in a solution with $P$. aeruginosa. However, they exhibited higher phase angles in a solution with $P$. aeruginosa.

Additionally, SRFs were measured when the sensors were placed in a solution with $C$. albicans or P. aeruginosa. The obtained SRFs were 157 and $172 \mathrm{kHz}$ for $C$. albicans and $P$. aeruginosa, respectively. Figure 9 shows capacitance as a function of frequency for $\mathrm{SnO}_{2}-600$ films exposed to C. albicans and P. aeruginosa, as well as the positions of resonance peaks and the SRF.

Agreement between the results in Table 4 and Fig. 9 can be observed. When the $\mathrm{SnO}_{2}-600$ sensor was placed in a solution with C. albicans, it had higher impedance magnitude at the same frequency than that when the sensor was placed in a solution with $P$. aeruginosa, which means that the IDC sensor had higher capacitance, and consequently lower SRF, when immersed in the solution with C. albicans.

This behavior can be attributed to the lower dielectric constant of bacteria than that of yeasts/fungi. ${ }^{(43)}$ The analyzed pathogens have different intrinsic structures and characteristics: C. albicans is a pathogenic yeast, whereas $P$. aeruginosa is a bacteria. The dielectric properties of yeasts/fungi and bacteria should be different because they have different cellular structures. Yeasts consist of various types of polysaccharides, which produce relatively thick cell walls. ${ }^{(43)}$

Table 4

Impedance magnitude and phase angle of sensors sintered at $600{ }^{\circ} \mathrm{C}$ immersed in solutions with C. albicans and $P$. aeruginosa.

\begin{tabular}{cccccc}
\hline & \multicolumn{2}{c}{ C. albicans } & & \multicolumn{2}{c}{$P$. aeruginosa } \\
${$\cline { 1 - 3 }$(\mathrm{kHz})} }$ & $Z(\Omega)$ & $\phi(\mathrm{deg})$ & & $Z(\Omega)$ & $\phi(\mathrm{deg})$ \\
\hline 60 & 11.852 & -1.938 & & 7.685 & -1.767 \\
\hline 120 & 11.719 & -0.938 & & 7.599 & -0.615 \\
\hline 180 & 11.663 & -0.332 & & 7.563 & 0.187 \\
\hline 240 & 11.632 & 0.161 & & 7.544 & 0.850 \\
\hline
\end{tabular}

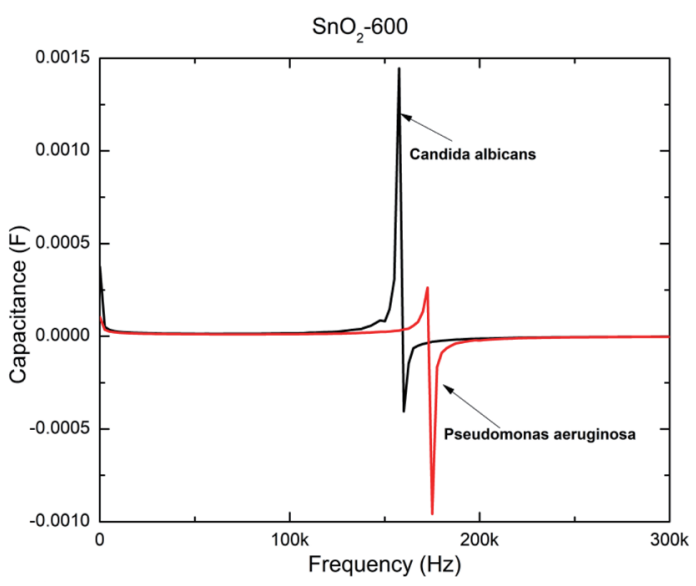

Fig. 9. (Color online) Capacitance as a function of frequency for $\mathrm{SnO}_{2}-600$ films exposed to C. albicans and $P$. aeruginosa. 
However, bacterial cell walls are relatively thin (mostly consisting of peptidoglycan). Moreover, yeasts are mainly composed of $\beta$-glucan (with long branches and a large molecular weight), while bacteria primarily consist of water. It has been reported that yeasts have a higher dielectric constant than bacteria, which is most probably due to the large polarizability of the branch structure of long-branched $\beta$-glucan. ${ }^{(41)}$ These results were also confirmed in an aqueous environment. Additionally, the results from Ref. 41 support our findings presented in Table 4 and Fig. 9.

The results presented in this article are of an initial investigation of the use of $\mathrm{SnO}_{2}$-based IDC sensors for selective pathogen detection (P. aeruginosa and C. albicans). We have shown that the different pathogens have different electrical responses, which can be expected from the theoretical analysis of the pathogen structure. For example, yeasts have a higher dielectric constant than bacteria, which led us to expect a higher capacitance and lower SRF for the case of $C$. albicans. Experimental results confirmed this expectation. Therefore, by performing impedance and SRF measurements on a larger number of different pathogens, it will be possible to recognize the unique pattern of changes in the electrical parameters corresponding to specific pathogens. The experimental and processed data in the proposed approach require very small computational resources for their storage, allowing larger datasets and increasing the reliability and accuracy of identification and selective detection.

\subsubsection{Comparison of proposed method with other methods for detecting and identifying pathogenic bacteria}

The results presented in Sect. 3.3.2 demonstrate an initial step towards the further development of a system for the reliable detection and identification of pathogenic bacteria in real-life applications. Because of this, it is very useful to also give a short overview of phenotypic and molecular diagnostic methods for the detection and identification of pathogenic bacteria, and to compare them with the IDC-sensor-based identification technique.

Phenotypic methods explore biochemical pathways, which are unique for specific bacteria. This approach enables bacterial identification, even though many proteins (and also enzymes) are common to different bacterial species. Phenotypic methods include biochemical testing, the chromogenic media approach, and matrix-assisted laser desorption/ionization-time-offlight mass spectrometry (MALDI-TOF MS). ${ }^{(44)}$ During the detection of specific pathogens in biochemical testing, it is necessary to use more specific culture media than general-purpose agar-based media (commonly used in clinical microbiology laboratories). An example of this approach is a differential media target, which combines systems for monitoring nutrition incorporation and indicators for monitoring digested nutrients. Bacteria can be identified with modern automated systems in just a few hours. ${ }^{(44)}$ In the chromogenic media approach, small amounts of the sample to be analyzed are placed on chromogenic substrates, which are then hydrolyzed. After such treatment, if enzymes of interest are present, the sample will develop a specific color. However, in practice, this approach produces results that require further confirmation by MALDI-TOF MS. In addition, 16 to $48 \mathrm{~h}$ is usually required to perform testing. ${ }^{(42)}$ MALDI-TOF MS is an ionization technique where ions are created from molecules by means 
of a matrix that absorbs laser energy. Identification is based on the time taken by ions to reach the detector, which is dependent on the charge of the ions and characteristic masses. Specialized software (an online database) is then used to compare the obtained mass spectra with defined profiles for specific bacteria. MALDI-TOF MS is suitable for applications where a large number of tests are required every day. ${ }^{(42)}$

Hybridization-based detection, amplification methods, and DNA microarrays are the most popular molecular diagnostic methods for bacterial detection. Hybridization-based detection is a very fast and reliable approach for detecting specific bacteria. A detection time of less than $2.5 \mathrm{~h}$ and accuracy of $96.5 \%$ have been reported. ${ }^{(44)}$ This approach uses fluorescent dyes with synthetic DNA fragments as probes. The presence of a specific species is determined from the fluorescent signal. Amplification methods are based on the isolation, amplification, and quantification of a short DNA sequence that corresponds to a specific bacterium. These methods usually require between 5 and $24 \mathrm{~h}$ for the complete process. DNA microarrays are becoming increasingly popular as modern computer systems allow access to publicly available large-scale whole genome sequencing data. Because of this, genes and combinations of genes of specific pathogens can be determined.

It is evident that, despite some techniques providing promising results, there is still a growing need for rapid, cost-efficient, and reliable systems for bacteria detection and identification. The IDC-sensor-based approach presented in this paper does not require expensive equipment for data processing as the sensing mechanism is based on impedance and SRF measurements. Moreover, the fabrication of IDC sensors is straightforward and economical. In addition, IDC sensors have small dimensions, which make them very suitable for portable systems and measurements outside the laboratory.

\section{Conclusions}

In this paper, we presented a $\mathrm{SnO}_{2}$ powder with nanosize particles synthesized by a coprecipitation method. TEM analyses confirmed the presence of the rutile tetragonal structure and a nanometer crystallite size $(<25 \mathrm{~nm})$. Interdigitated capacitive $\mathrm{SnO}_{2}$ structures were fabricated from this nanopowder using screen-printing technology. Samples were sintered at 600,700 , and $800{ }^{\circ} \mathrm{C}$ on an $\mathrm{Al}_{2} \mathrm{O}_{3}$ substrate. From the calculation using Scherrer's equation, it was confirmed that the grain size of the $\mathrm{SnO}_{2}$ films was in the range of $16-25 \mathrm{~nm}$. Using impedance spectroscopy, the response of $\mathrm{SnO}_{2}$ films to C. albicans and P. aeruginosa was monitored. Impedance spectroscopic studies of the response in a C. albicans medium revealed that the sensitivity of the film tended to decrease with increasing sintering temperature and crystallite size. Owing to the lowest crystallite size and highest density of active sites on the surface, the $\mathrm{SnO}_{2}-600$ film showed the highest sensitivity to the pathogen media. All tested samples showed a characteristic SRF shift that depended on the sensor structure and the exposed pathogen medium.

The main contributions of this article can be summarized as follows: (1) analysis of the effect of the sintering temperature on the sensing characteristics of $\mathrm{SnO}_{2}$ films, and (2) analysis and explanation of the sensing mechanism of $\mathrm{SnO}_{2}$ films sintered at the same temperature but 
exposed to different pathogen media. The future direction of this study will be oriented towards the development of similar sensor structures on flexible substrates to implement them in reallife applications.

\section{Acknowledgments}

This work also received funding from the European Union's Horizon 2020 research and innovation programme under Marie Skłodowska-Curie grant No. 813680. GF acknowledges Slovenian Research Agency (ARRS grant L2-6769) for financial support. MS would like to thank the Ministry of Scientific and Technological Development, Higher Education and Information Society of the Republic of Srpska for support within project No. 19.032/961-83/19.

\section{References}

1 M. Tonezzer, J. H. Kim, J. H. Lee, S. Iannotta, and S. S. Kim: Sens. Actuators, B 281 (2019) 670. https://doi. org/10.1016/j.snb.2018.10.102

2 H. Puliyalil, P. Slobodian, M. Sedlacik, R. Benlikaya, P. Riha, K. Ostrikov, and U. Cvelbar: Front Chem. Sci. Eng. 10 (2016) 265. https://doi.org/10.1007/s11705-016-1570-6

3 L. Manjakkal, K. Cvejin, J. Kulawik, K. Zaraska, D. Szwagierczak, and R. P. Socha: Sens. Actuators, B 204 (2014) 57. https://doi.org/10.1016/j.snb.2014.07.067

4 S. Laschi and M. Mascini: Med. Eng. Phys. 28 (2006) 934. https://doi.org/10.1016/j.medengphy.2006.05.006

5 E. Rahmanian, C. C. Mayorga Martinez, R. Malekfar, J. Luxa, Z. Sofer, and M, Pumera: ACS Appl. Nano Mater. 1 (2018) 7006. https://doi.org/10.1021/acsanm.8b01796

6 H. C. Wang, Y. Li, and M. J. Yang: Sens. Actuators, B 119 (2006) 380. https://doi.org/10.1016/j.snb.2005.12.037

7 S. Li, X. Zhong, Y. Song, X. Shen, J. Sun, Y. Song, R. Wang, M. Zhu, H. Zhong, and A. Zheng: J. Mater. Chem. C. 2 (2014) 7687. https://doi.org/10.1039/C4TC00842A

8 N. Chiodini, A. Paleari, D. DiMartino, and G. Spinolo: Appl. Phys. Lett. 81 (2002) 1702. https://doi. org/10.1063/1.1503154

9 L. Jiang, G. Sun, Z. Zhou, S. Sun, Q. Wang, S. Yan, H. Li, J. Tian, J. Guo, B. Zhou, and Q. Xin: J. Phys. Chem. B. 109 (2005) 8774. https://doi.org/10.1021/jp050334g

10 X. Liu, T. Ma, Y. Xu, L. Sun, L. Zheng, O. G. Schmidt, and J. Zhang: Sens. Actuators, B 264 (2018) 92. https:// doi.org/10.1016/j.snb.2018.02.187

11 S. H. Nam and J. H. Boo: J. Nanosci. Nanotechno. 12 (2012) 1559. https://doi.org/10.1166/jnn.2012.4650

12 S. Rehman, S. M. Asiri, F. A. Khan, B. R. Jermy, H. Khan, S. Akhtar, R. A. Jindan, K. M Khan, and A. Qurashi: ChemistrySelect 4 (2019) 4013. https://doi.org/10.1002/slct.201803550

13 E.M. El-Maghraby, A. Qurashi, and T. Yamazaki, Ceram. Int. 39 (2013) 8475. https://doi.org/10.1016/ j.ceramint.2013.01.112

14 N. Pinna, G. Neri, M. Antonietti, and M. Niederberger: Angew. Chem. Int. Edit. 116 (2004) 4445. https://doi. org/10.1002/ange.200460610

15 H. Puliyalil and U. Cvelbar: Nanomaterials 6 (2016) 108. https://doi.org/10.3390/nano6060108

16 A. L. Linsebigler, G. Lu, and J. T. Yates: Chem. Rev. 95 (1995) 735. https://doi.org/10.1021/cr00035a013

17 J. R. Heath, C. M. Knobler, and D. V. Leff: J. Phy. Chem. B 101 (1997) 189. https://doi.org/10.1021/jp9611582

18 V. Nair, C. L. Perkins, Q. Lin, and M. Law: Energy Environ. Sci. 9 (2016) 1412. https://doi.org/10.1039/ C6EE00129G

19 A. Cirera, A. Vilà, A. Diéguez, A. Cabot, A. Cornet, and J. R. Morante: Sens. Actuators, B 64 (2000) 65. https://doi.org/10.1016/S0925-4005(99)00485-2

20 P. Siciliano: Sens. Actuators, B 70 (2000) 153. https://doi.org/10.1016/S0925-4005(00)00585-2

21 I. Simon, N. Bârsan, M. Bauer, and U. Weimar: Sens. Actuators, B 73 (2001) 1. https://doi.org/10.1016/S09254005(00)00639-0

22 T. Hyeon: Chem. Commun. 8 (2003) 927. https://doi.org/10.1039/B207789B

23 S. Sun and H. Zeng: J. Am. Chem. Soc. 124 (2002) 8204. https://doi.org/10.1021/ja026501x

24 V. Subramanian, E. E. Wolf, and P. V. Kamat: J. Am. Chem. Soc. 126 (2004) 4943. https://doi.org/10.1021/ ja0315199 
25 M. Niederberger: Accounts Chem. Res. 40 (2007) 793. https://doi.org/10.1021/ar600035e

26 F. Hadef: An Introduction to Nanomaterials: Environmental Nanotechnology (Springer, Heidelberg, 2018). p. 1. Chap. 1.

27 R. G. S. V. Prasad, A. R. Phani, K. N. Rao, R. R. Kumar, S. Prasad, G. Prabhakara, M. S. Sheeja, C. P. Salins, J. L. Endrino, and D. B. Raju: J. Biomed Nanotechnol. 11 (2015) 942. https://doi.org/10.1166/jbn.2015.2025

28 K. Flynn, B. P. Villarreal, A. Barranco, N. Belc, B. Björnsdóttir, V. Fusco, S. Rainieri, S. E. Smaradóttir, I. Smeu, P. Teixeira, and H. Ó. Jörundsdóttir: Trends Food Sci. Technol. 84 (2019) 1. https://doi.org/10.1016/j.tifs.2018.09.012

29 B. M. Chassy: New Biotechnol. 27 (2010) 534. https://doi.org/10.1016/j.nbt.2010.05.018

30 F. Adzitey, N. Huda, and G. R. R. Ali: Biotech. 3 (2013) 97. https://doi.org/10.1007/s13205-012-0074-4

31 R. H. Hall: Microbes Infect. 4 (2002) 425. https://doi.org/10.1016/s1286-4579(02)01556-3

32 Y. Wang, Z. Ye, and Y. Ying: Sens. 12 (2012) 3449. https://doi.org/10.3390/s120303449

33 P. Silley and S. Forsythe: J. Appl Bacteriol. 80 (1996) 233. https://doi.org/10.1111/j.1365-2672.1996.tb03215.x

34 G. N. Stewart: J Exp Med. 4 (1899) 235. https://doi.org/10.1084/jem.4.2.235

35 J. C. S. Richards, A. C. Jason, G. Hobbs, D. M. Gibson, and R. H. Christie: J. Phys. E 11 (1978) 560. https:// doi.org/10.1088/0022-3735/11/6/017

36 P. Cady, S. W. Dufour, J. Shaw, and S. J. Kraeger, J. Clin. Microbiol. 7 (1978) 265

37 P. C. Joshi and M. W. Cole: J. Appl Phys., 86 (1999) 871. https://doi.org/10.1063/1.370817

38 B. G. Pawar, D. V. Pinjari, S. S. Kolekar, A. B. Pandit, and S. H. Han: Int. Sch. Res. Notices 2012 (2012) 1. https://doi.org/10.5402/2012/954869

39 G.Korotcenkov: Sens. Actuators, B 107 (2005) 209. https://doi.org/10.1016/j.snb.2004.10.006

40 J. Zuo, C. Xu, X. Liu, C. Wang, C. Wang, Y. Hu, and Y. Qian: J. Appl. Phys. 75 (1994) 1835. https://doi. org/10.1063/1.356348

41 M. A. Bhuiyan, S. M. Hoque, and S. Choudhury: J. Bangladesh Acad. Sci. 34 (2010) 189. https://doi. org/10.3329/jbas.v34i2.6865

42 A. R. C. Bredar, A. L. Chown, A. R. Burton, and B. H. Farnum: ACS Appl. Energy Mater. 3 (2020) 66. https:// doi.org/10.1021/acsaem.9b01965

43 S. A. Yoon, S. H. Cha, S. W. Jun, S. J. Park, J.-Y. Park, S. Lee, H. S. Kim, and Y. H. Ahn: Biomed. Opt .Express 11 (2020) 406. https://doi.org/10.1364/BOE.376584

44 L.Varadi, J. L. Luo, D. E. Hibbs, J. D. Perry, R. J. Anderson, S. Orengae, and P. W. Groundwater: Chem. Soc. Rev. 46 (2017) 4818. https://doi.org/10.1039/c6cs00693k 